\title{
Effect of intrathecal dexmedetomidine on preventing shivering in cesarean section after spinal anesthesia: a meta-analysis and trial sequential analysis
}

This article was published in the following Dove Press journal: Drug Design, Development and Therapy

\author{
Shuai Miao* \\ Mengzhu Shi* \\ Lan Zou \\ Guanglei Wang \\ Department of Anesthesiology, The \\ Affiliated Hospital of XuZhou Medical \\ University, XuZhou, JiangSu, China \\ *These authors contributed equally \\ to this work
}

\begin{abstract}
Objective: Intrathecal dexmedetomidine (DEX) has been used to prevent shivering in patients undergoing cesarean section. The aim of this meta-analysis was to evaluate whether intrathecal DEX could prevent shivering in cesarean section after spinal anesthesia.

Methods: We searched PubMed, Embase, Web of Science, and the Cochrane Library for randomized controlled trials (RCTs) comparing intrathecal DEX in cesarean section after spinal anesthesia with placebo and reporting on shivering, postoperative nausea and vomiting (PONV), hypotension, and bradycardia. Trial sequential analysis (TSA) was also carried out for RCTs comparing DEX with placebo. This meta-analysis has been registered on PROSPERO, and the registration number is CRD42017071640.
\end{abstract}

Results: Six randomized clinical trials comparing 360 patients were included in this study. Compared with placebo, intrathecal DEX significantly reduced the incidence of shivering (risk ratio $[\mathrm{RR}]=0.40 ; 95 \% \mathrm{CI}[0.26,0.62] ; P<0.0001)$. No significant difference was found in the incidence of PONV ( $R R=1.34 ; 95 \%$ CI [0.82, 2.18]; $P=0.24)$, hypotension ( $R R=1.09 ; 95 \% \mathrm{CI}$ $[0.84,1.42] ; P=0.50)$, or bradycardia ( $\mathrm{RR}=1.55 ; 95 \% \mathrm{CI}[0.54,4.42] ; P=0.42)$. However, no firm conclusions can be made based on the results of all outcomes according to the TSA.

Conclusion: This meta-analysis found that intrathecal DEX could prevent shivering in cesarean section after spinal anesthesia and did not induce PONV, hypotension, or bradycardia. However, firm conclusions cannot be made until more studies are conducted.

Keywords: dexmedetomidine, cesarean section, spinal anesthesia, meta-analysis, trial sequential analysis, adverse effect

\section{Introduction}

Spinal anesthesia has been widely used to provide anesthesia and analgesia for cesarean section, which allows a patient to remain awake for the birth of her baby while avoiding the risks of general anesthesia. ${ }^{1-3}$ Even though the risk of spinal anesthesia is lower than that of general anesthesia, the adverse events caused by spinal anesthesia, such as shivering, are still present during surgical procedures, causing discomfort for the patients..$^{4,5}$

The incidence of shivering is up to $55 \%$ according to a previously published study. ${ }^{6}$ Shivering may lead to increased oxygen consumption and negative effects on pulse, oxygen saturation, and blood pressure. Severe adverse effects may occur if the patient has cardiopulmonary insufficiency. ${ }^{6,7}$ 
Dexmedetomidine (DEX), as a highly selective $\alpha-2$ adrenoreceptor agonist, can provide some beneficial effects when administered through the spinal route, such as sedation, analgesia, antianxiety effects, and increased threshold of shivering. ${ }^{89}$ Some randomized controlled trials (RCTs) have been conducted to estimate the effects of intrathecal DEX on shivering. However, the effect of intrathecal DEX on shivering in cesarean section after spinal anesthesia remains controversial. Therefore, we conducted this meta-analysis from relevant studies to evaluate the effects of intrathecal DEX on shivering in cesarean section after spinal anesthesia. Additionally, trial sequential analysis (TSA) was carried out for RCTs comparing DEX with placebo.

\section{Subjects and methods Protocol and registration}

We followed the recommendations of the Cochrane Handbook for Systematic Reviews of Interventions ${ }^{10}$ and the PRISMA recommendations to conduct the present meta-analysis. ${ }^{11}$ The protocol has been registered in the PROSPERO international database under number CRD42017071640.

\section{Search strategy}

Two authors searched PubMed, Embase, Web of Science, and the Cochrane Library using search terms ("dexmedetomidine", "cesarean section", "cesarean delivery", "spinal anesthesia") up to March 31, 2018, without language restriction. We also manually searched for the references of the identified trials and systematic reviews to identify any potentially relevant trials. Titles, abstracts, and full texts of potentially relevant articles were screened after excluding duplicated ones.

\section{Eligibility criteria}

The following were the eligibility criteria:

- Participants: adult patients undergoing cesarean section after spinal anesthesia.

- Interventions: any study was considered if DEX was delivered via intrathecal route.

- Comparisons: patients who were exposed to placebo.

- Outcomes: at least one of the following outcomes was reported in the studies: incidence of shivering, postoperative nausea and vomiting (PONV), hypotension, or bradycardia.

- Study design: only RCTs were regarded as eligible for this meta-analysis.

\section{Study selection and data extraction}

Two authors independently identified the studies for inclusion according to the eligibility criteria. Any disagreement was resolved by consensus. The following data were extracted from each included study: first author, country, year of publication, number of participants, intervention details, and trial characteristics. The primary outcome was shivering, and the secondary outcomes included PONV, hypotension, and bradycardia.

\section{Assessment of study quality}

Two authors independently assessed the risk of bias in the included studies. The following factors were assessed according to the Cochrane risk of bias tool for each study: ${ }^{12}$ 1) random sequence generation; 2) allocation concealment; 3) blinding of participants and personnel; 4) blinding of outcome assessors; 5) incomplete outcome data; and 6) selective outcome reporting and other bias. Trials were classified as having low, unclear, or high risk of bias on each domain. Trials were considered to have a high risk of bias if one or more of these domains were scored as unclear or high risk of bias.

\section{Statistical analyses}

All the statistical analyses were conducted using Review Manager, version 5.3 (The Nordic Cochrane Center, The Cochrane Collaboration, Copenhagen, 2014). Dichotomous outcomes were reported by the risk ratio (RR) and 95\% CI. Heterogeneity was assessed with the $I^{2}$ statistic. ${ }^{13}$ We selected the random-effects model to calculate pooled effects, regardless of whether $I^{2}$ was $\geq 50 \%$.

Subgroup analysis and sensitivity analysis were performed on factors that may have contributed to the heterogeneity. Subgroup analysis was carried out according to the drug dosage (5 and $10 \mu \mathrm{g}$ ). Sensitivity analysis was performed by using both the random-effects and fixed-effects analysis models. ${ }^{14}$ Sensitivity analysis was also performed by removing one study at a time to assess the effect of each study on the overall effect size.

\section{TSA}

The reliability and conclusiveness of the available evidence were examined by TSA, which can reduce false-positive results caused by multiple testing and sparse data. ${ }^{15,16} \mathrm{We}$ calculated the required information size (RIS) and the trial sequential monitoring boundaries for all outcomes. 
The variance was calculated from the data obtained from the included studies. If the cumulative $Z$ curve crossed the TSA boundary, a sufficient level of evidence for the anticipated intervention effect may have been reached and no further studies are needed. However, if the $Z$ curve failed to cross the TSA boundaries and the RIS has not been reached, evidence to reach a conclusion is insufficient. We used two-sided tests with a type I error of $5 \%$, a power of $80 \%$, and a relative risk reduction of $20 \%$ to calculate the RIS. ${ }^{17}$

\section{Results}

\section{Trial selection}

Figure 1 shows a summary of the study selection process. We identified 104 studies through database searching. After excluding duplicate references and reviewing titles and abstracts, we selected 13 studies for full-text evaluation. Of these, seven trials did not meet the inclusion criteria or the exclusion criteria. The main reasons for exclusion included that the study was not randomized $(n=1)$, that DEX was not given by intrathecal route $(n=5)$, or that the study did not report outcomes that we needed $(n=1)$. Finally, six studies were included. ${ }^{18-23}$

\section{Characteristics and quality of included studies}

Table 1 shows the details of all the studies included in the meta-analysis. All studies used bupivacaine as the local anesthetic. However, the dose of DEX was different between the studies. In all, $10 \mu \mathrm{g}$ of DEX was used in two studies and $5 \mu \mathrm{g}$ of DEX was used in the other four trials. Two authors independently evaluated the quality of all the RCTs. All the six studies were classified as low risk of bias, and details of the risk of bias for all of the included studies are shown in Figure 2.

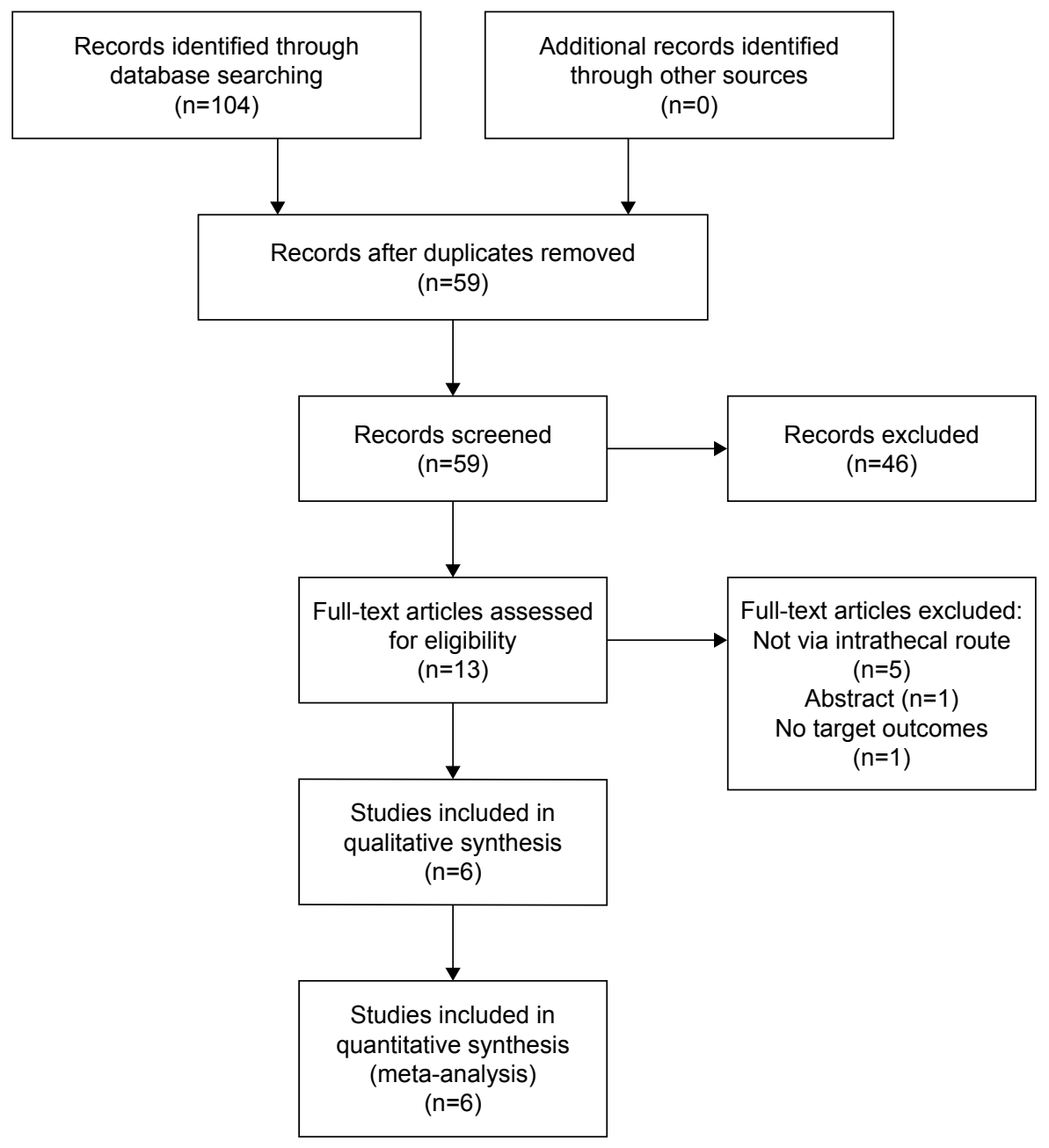

Figure I PRISMA flowchart of the included studies. 
Table I Characteristics of all the trials included in the meta-analysis

\begin{tabular}{|c|c|c|c|c|c|c|}
\hline \multirow[t]{2}{*}{ Study } & \multirow[t]{2}{*}{ Country } & \multicolumn{2}{|c|}{ No of participants } & \multirow{2}{*}{$\begin{array}{l}\text { Administration } \\
\text { route }\end{array}$} & \multicolumn{2}{|l|}{ Intervention } \\
\hline & & DEX & Control & & Experimental group & Control group \\
\hline Li et al ${ }^{18}$ & China & 21 & 21 & Spinal & $\begin{array}{l}\text { Bupivacaine } 4 \mathrm{~mL} \\
(10 \mathrm{mg})+\mathrm{DEX} 10 \mu \mathrm{g}\end{array}$ & Bupivacaine $4 \mathrm{~mL}$ (10 mg) \\
\hline Sun et al ${ }^{19}$ & China & 30 & 30 & Spinal & $\begin{array}{l}\text { Bupivacaine } 0.5 \% 2 \mathrm{~mL} \\
(10 \mathrm{mg})+\mathrm{DEX} 10 \mu \mathrm{g}\end{array}$ & $\begin{array}{l}\text { Bupivacaine } 0.5 \% 2 \mathrm{~mL} \\
(10 \mathrm{mg})+1.0 \mathrm{~mL} 0.9 \% \text { saline }\end{array}$ \\
\hline Qi et $\mathrm{al}^{20}$ & China & 39 & 39 & Spinal & $\begin{array}{l}\text { Bupivacaine } 0.5 \% \\
2 \mathrm{~mL}+\text { DEX } 5 \mu \mathrm{g}\end{array}$ & Bupivacaine $0.5 \% 2.0 \mathrm{~mL}$ \\
\hline $\begin{array}{l}\text { Nasseri } \\
\text { et a }{ }^{21}\end{array}$ & Iran & 25 & 25 & Spinal & $\begin{array}{l}\text { Bupivacaine } 0.5 \% \\
12.5 \mathrm{mg}+\mathrm{DEX} 5 \mu \mathrm{g}\end{array}$ & $\begin{array}{l}\text { Bupivacaine } 0.5 \% \text { I } 2.5 \mathrm{mg}+0.5 \mathrm{~mL} \\
0.9 \% \text { saline }\end{array}$ \\
\hline He et $a^{22}$ & China & 45 & 45 & Spinal & $\begin{array}{l}\text { Bupivacaine } 0.5 \% \\
2.5 \mathrm{~mL}+\mathrm{DEX} 5 \mu \mathrm{g}\end{array}$ & $\begin{array}{l}\text { Bupivacaine } 0.5 \% 2.5 \mathrm{~mL}+0.5 \mathrm{~mL} \\
0.9 \% \text { saline }\end{array}$ \\
\hline $\mathrm{Bi}$ et $\mathrm{a}^{23}$ & China & 20 & 20 & Spinal & $\begin{array}{l}\text { Bupivacaine } \\
10 \mathrm{mg}+\mathrm{DEX} 5 \mu \mathrm{g}\end{array}$ & Bupivacaine $10 \mathrm{mg}$ \\
\hline
\end{tabular}

Abbreviation: DEX, dexmedetomidine.

\section{Outcomes of the meta-analysis Shivering}

All studies reported the incidence of shivering. Data extracted from relevant studies indicated that the addition of DEX

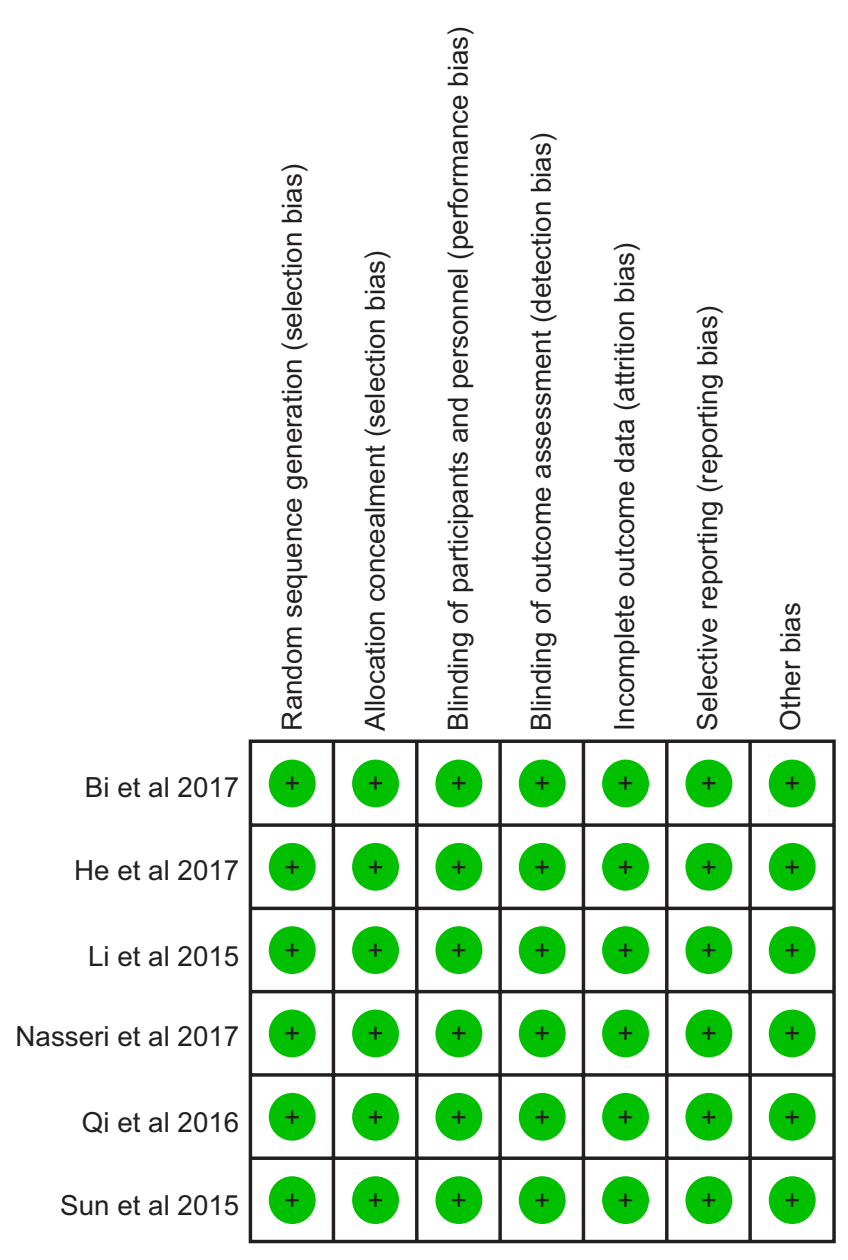

Figure 2 The risk of bias of all the included trials. significantly reduced the incidence of shivering $(R R=0.40$, 95\% CI [0.26, 0.62]; Figure 3) according to conventional meta-analysis. The TSA indicated that the $Z$ curve failed to cross the TSA boundary and did not reach the RIS but crossed the conventional boundary (Figure 4).

Subgroup analysis showed that the only the application of DEX $5 \mu \mathrm{g}(\mathrm{RR}=0.41,95 \% \mathrm{CI}[0.26,0.63])$ was significantly more effective than that of placebo for the prevention of shivering, while no difference was found between the two groups when DEX $10 \mu \mathrm{g}$ was injected.

Heterogeneity was found in the incidence of shivering; therefore, sensitivity analysis was performed. By removing one study at a time, the sensitivity analysis had no effect on the result.

\section{PONV}

All six studies reported PONV. It was found that the addition of DEX did not reduce the risk of PONV ( $R R=1.34$, 95\% CI [0.82, 2.18]; Figure 5). The TSA indicated that the $Z$ curve failed to cross the conventional boundary or the TSA boundary (Figure 6).

\section{Hypotension}

Data from five studies involving 320 participants showed that the risk of hypotension was similar in the two groups $(\mathrm{RR}=1.09,95 \% \mathrm{CI}[0.84,1.42]$; Figure 7). The TSA indicated that the $Z$ curve failed to cross the conventional boundary or the TSA boundary (Figure 8).

\section{Bradycardia}

Five studies reported data about the occurrence of bradycardia, which showed that the rate of bradycardia in the DEX group was similar to that in the control group $(R R=1.55$, 


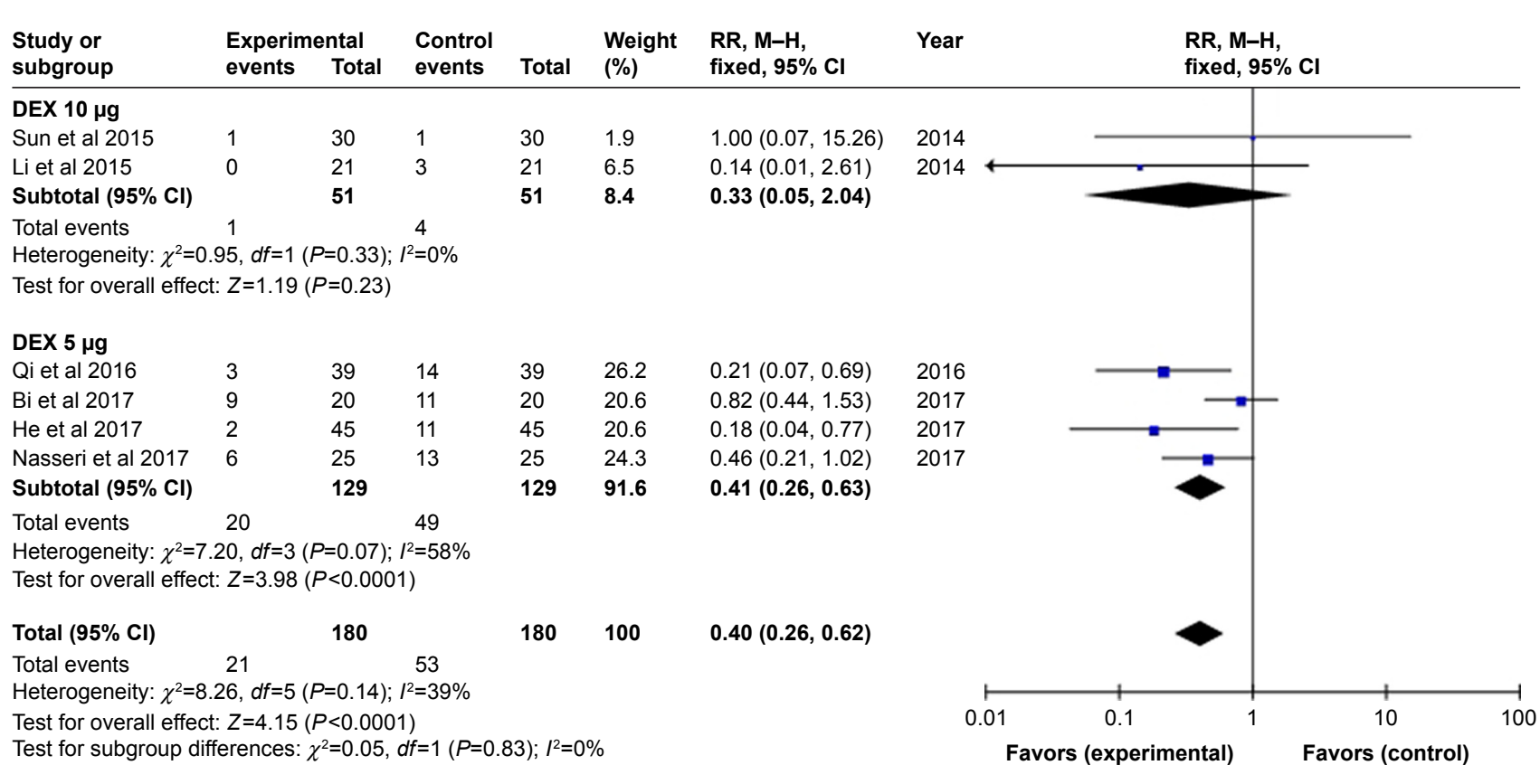

Figure 3 Forest plot for the incidence of shivering with and without DEX.

Abbreviations: DEX, dexmedetomidine; RR, risk ratio; $\mathrm{M}-\mathrm{H}$, Mantel-Haenszel.

95\% CI [0.54, 4.42]; Figure 9). There was too little information to conduct the TSA boundary.

\section{Discussion}

For the present study, we retrieved six RCTs to investigate the effect of DEX as a neuraxial adjuvant in cesarean section.
We found that spinal administration of DEX could effectively prevent perioperative shivering but did not increase the incidence of PONV or induce bradycardia and hypotension.

DEX is a highly selective $\alpha 2$-adrenergic receptor agonist and can provide many beneficial effects, such as sedation, analgesia, perioperative sympatholysis, and synesthetic

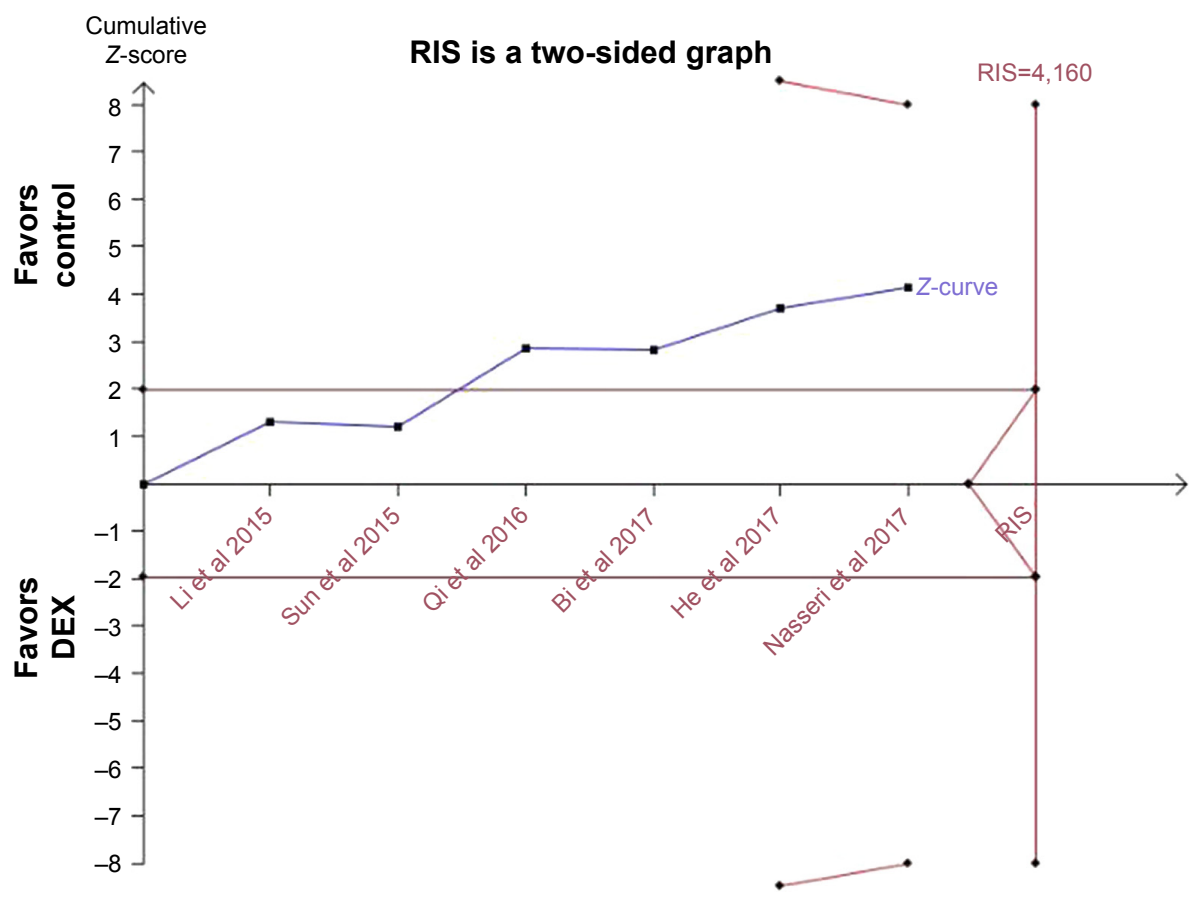

Figure 4 TSA evaluating the incidence of shivering with and without DEX.

Abbreviations: TSA, trial sequential analysis; DEX, dexmedetomidine; RIS, required information size. 


\begin{tabular}{|c|c|c|c|c|c|c|}
\hline $\begin{array}{l}\text { Study or } \\
\text { subgroup }\end{array}$ & $\begin{array}{l}\text { DEX } \\
\text { events }\end{array}$ & Total & $\begin{array}{l}\text { Control } \\
\text { events }\end{array}$ & Total & $\begin{array}{l}\text { Weight } \\
(\%)\end{array}$ & $\begin{array}{l}\text { RR M-H, } \\
\text { fixed, } 95 \% \mathrm{Cl}\end{array}$ \\
\hline Li et al 2015 & 2 & 21 & 1 & 21 & 4.9 & $2.00(0.20,20.41)$ \\
\hline Sun et al 2015 & 2 & 30 & 1 & 30 & 4.9 & $2.00(0.19,20.90)$ \\
\hline Qi et al 2016 & 5 & 39 & 4 & 39 & 19.5 & $1.25(0.36,4.31)$ \\
\hline Bi et al 2017 & 4 & 20 & 0 & 20 & 2.4 & $9.00(0.52,156.91)$ \\
\hline Nasseri et al 2017 & 12 & 25 & 12 & 25 & 58.5 & $1.00(0.56,1.78)$ \\
\hline He et al 2017 & 2 & 45 & 2 & 45 & 9.8 & $1.00(0.15,6.79)$ \\
\hline Total $(95 \% \mathrm{Cl})$ & & 180 & & 180 & 100 & $1.34(0.82,2.18)$ \\
\hline Total events & 27 & & 20 & & & \\
\hline \multicolumn{7}{|c|}{ Heterogeneity: $\chi^{2}=3.03, d f=5(P=0.70) ; I^{2}=0 \%$} \\
\hline
\end{tabular}

Figure 5 Forest plot for the incidence of PONV with and without DEX.

Abbreviations: PONV, postoperative nausea and vomiting; DEX, dexmedetomidine; RR, risk ratio; M-H, Mantel-Haenszel.

sparing, without depressing respiration..$^{24,25}$ Because of these beneficial effects, DEX is widely used clinically, including for cesarean section. ${ }^{18,26}$ However, when administered by intravenous route, DEX can induce some negative side effects, such as bradycardia and hypotension. ${ }^{27}$ To decrease side effects, some clinicians choose to decrease the dose or change the administration route. Several studies demonstrated that epidural administration of DEX could provide some beneficial effects, including sedation, analgesia, and antianxiety effects. ${ }^{24,25}$

Shivering is one of the common complications of neuraxial anesthesia and causes discomfort and dissatisfaction in patients undergoing cesarean section. It was reported ${ }^{6}$ that the incidence of shivering after regional anesthesia was up to $55 \%$ and the incidence in cesarean section may be even higher. ${ }^{28}$ Shivering increases the consumption of oxygen and production of $\mathrm{CO}_{2}$ and may also intensify postoperative pain. ${ }^{29}$ The reasons for shivering may include suppression of spinal reflex activity, decrease in sympathetic activity, and inhibition of adrenal function. ${ }^{30}$ Many studies reported that DEX could effectively reduce the incidence of shivering during neuraxial anesthesia in patients undergoing cesarean section, without any associated respiratory depression as with other antishivering drugs, such as meperidine. ${ }^{18-22}$ The present

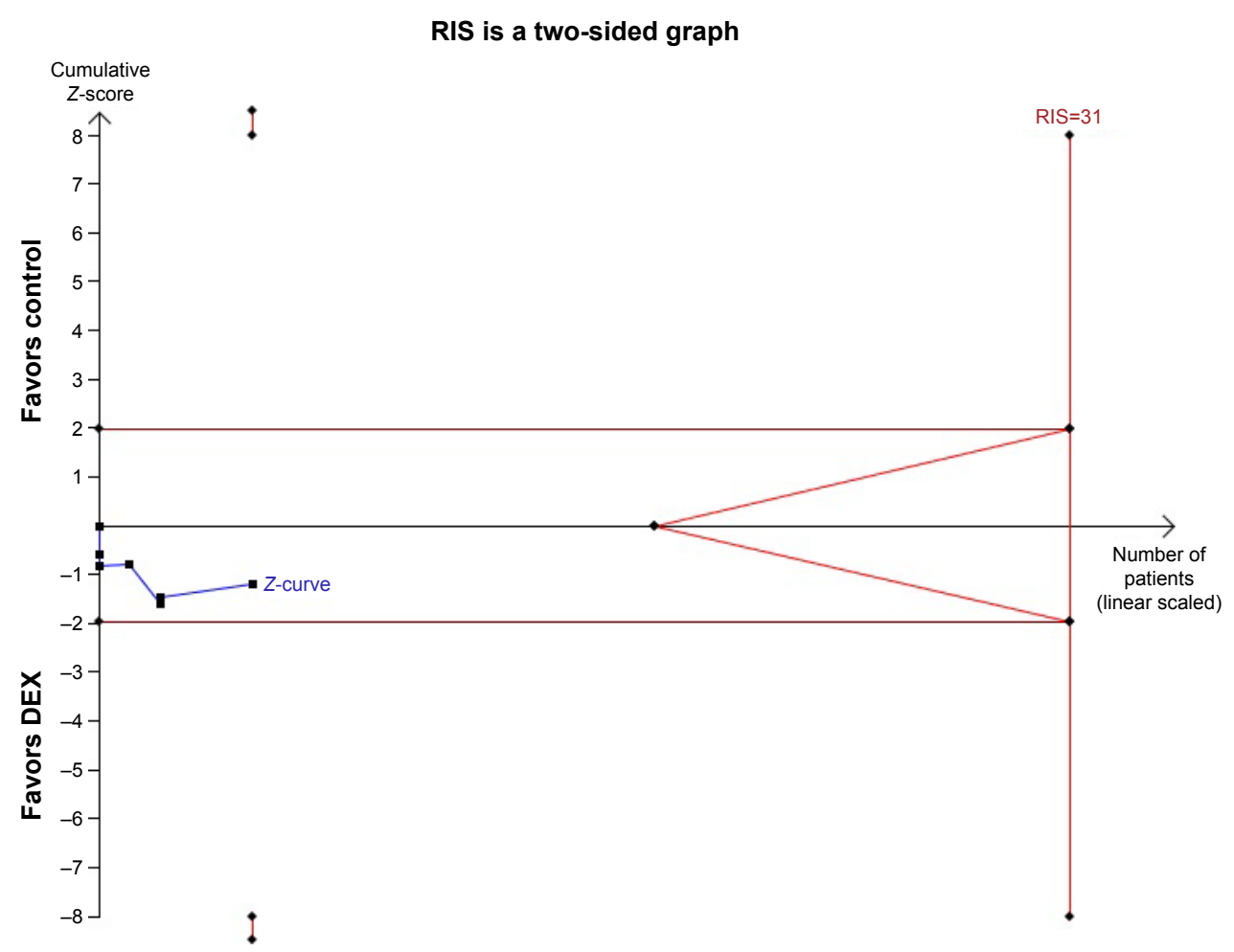

Figure 6 TSA evaluating the incidence of PONV with and without DEX.

Abbreviations: TSA, trial sequential analysis; PONV, postoperative nausea and vomiting; DEX, dexmedetomidine; RIS, required information size. 


\begin{tabular}{llllll}
$\begin{array}{l}\text { Study or } \\
\text { subgroup }\end{array}$ & $\begin{array}{l}\text { DEX } \\
\text { events }\end{array}$ & Total & $\begin{array}{l}\text { Control } \\
\text { events }\end{array}$ & Total & $\begin{array}{l}\text { W } \\
(\%)\end{array}$ \\
\hline Li et al 2015 & 3 & 21 & 3 & 21 & 7.1 \\
Sun et al 2015 & 4 & 30 & 4 & 30 & 9.4 \\
Qi et al 2016 & 15 & 39 & 12 & 39 & 28.2 \\
He et al 2017 & 1 & 45 & 0 & 45 & 1.2 \\
Nasseri et al 2017 & 23 & 25 & 23 & 25 & 54.1 \\
$\begin{array}{l}\text { Total }(95 \% \text { Cl) } \\
\text { Total events }\end{array}$ & $46 \quad 160$ & & 160 & 100 \\
Heterogeneity: $\chi^{2}=1.76, d f=4(P=0.78) ; I^{2}=0 \%$ & & \\
Test for overall effect: $Z=0.67(P=0.50)$ & & &
\end{tabular}

Figure 7 Forest plot for the incidence of hypotension with and without DEX.

Abbreviations: DEX, dexmedetomidine; RR, risk ratio; $\mathrm{M}-\mathrm{H}$, Mantel-Haenszel.

meta-analysis showed the same results reported in previous clinical trials. Some studies demonstrated that DEX could increase the temperature range without triggering thermoregulatory defenses by stimulating central $\alpha_{2}$-adrenergic receptors, thereby decreasing the central thermoregulatory threshold for shivering. ${ }^{31-33}$ The antishivering effect of intrathecal DEX may be caused by decreasing the shivering threshold. ${ }^{34}$ Additionally, DEX could prevent postoperative shivering by attenuating the hyperadrenergic response to perioperative stress. ${ }^{35}$ The data from four studies showed that the incidence of shivering was significantly lower than that in placebo when given DEX $5 \mu \mathrm{g}$, revealing that the low dosage of DEX may be more efficacious.
The present meta-analysis showed that, unlike opioids, DEX did not increase the incidence of PONV caused by cesarean section. PONV is a common complication of cesarean section. The causes for PONV during cesarean section include hypotension, visceral traction, and vagal stimulation, and among them, hypotension may be the most common cause. ${ }^{36,37}$ It was reported that compared with intravenous infusion, intrathecal DEX seldom induced hypotension, ${ }^{38}$ which is in accordance with the meta-analysis and why spinal administration of DEX would not increase the incidence of PONV. Opioids, which are the most common neuraxial adjuvants to local anesthetics, have many disadvantages, including PONV. Several studies reported that the usage of

RIS is a two-sided graph

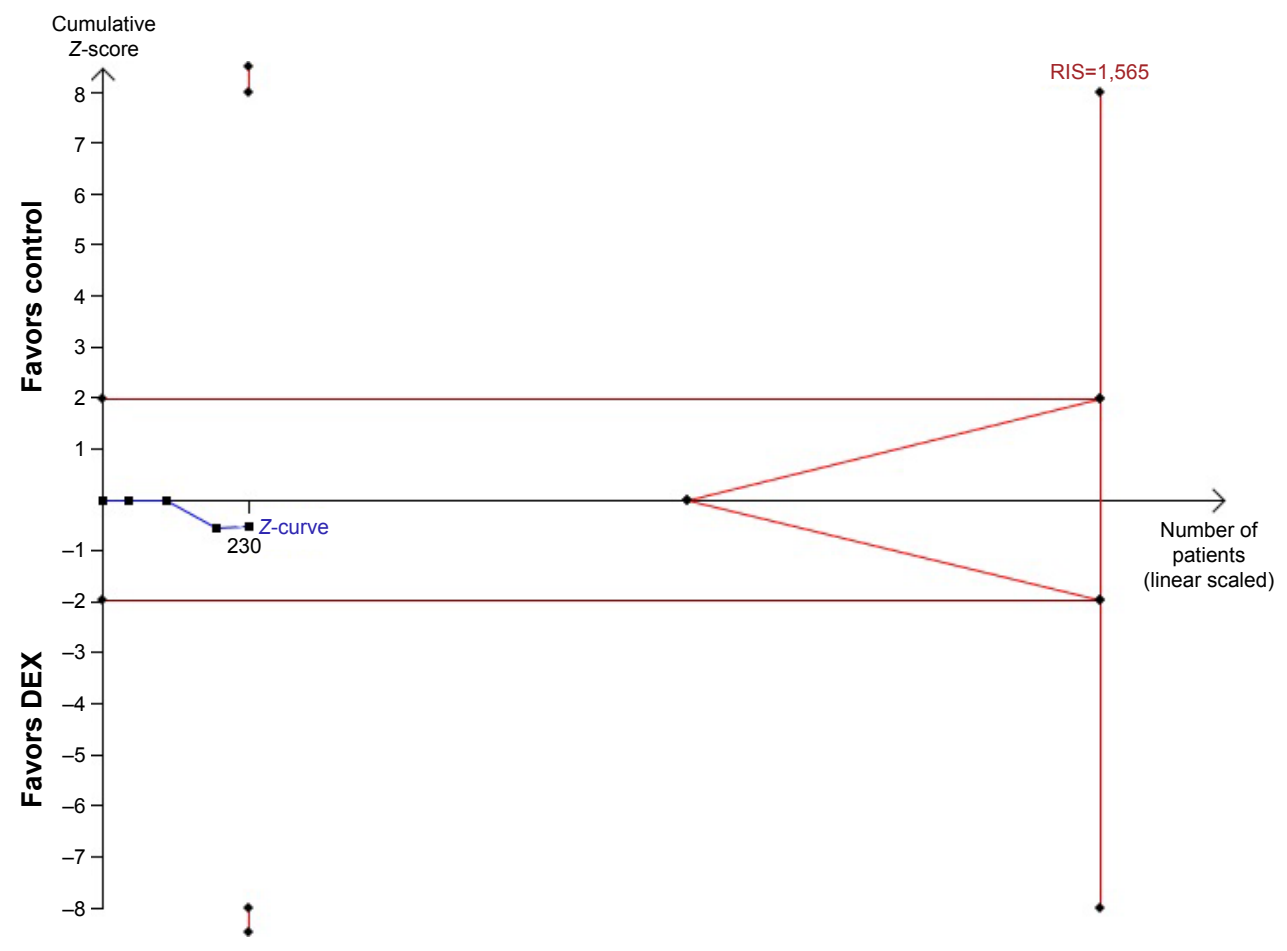

Figure 8 TSA evaluating the incidence of hypotension with and without DEX.

Abbreviations: TSA, trial sequential analysis; DEX, dexmedetomidine; RIS, required information size. 


\begin{tabular}{|c|c|c|c|c|c|}
\hline $\begin{array}{l}\text { Study or } \\
\text { subgroup }\end{array}$ & $\begin{array}{l}\text { DEX } \\
\text { events }\end{array}$ & Total & $\begin{array}{l}\text { Control } \\
\text { events }\end{array}$ & Total & $\begin{array}{l}\text { Weight } \\
(\%)\end{array}$ \\
\hline Li et al 2015 & 1 & 21 & 1 & 21 & 18.2 \\
\hline Sun et al 2015 & 2 & 30 & 1 & 30 & 18.2 \\
\hline Qi et al 2016 & 3 & 39 & 1 & 39 & 18.2 \\
\hline Nasseri et al 2017 & 1 & 25 & 2 & 25 & 36.4 \\
\hline He et al 2017 & 1 & 45 & 0 & 45 & 9.1 \\
\hline Total $(95 \% \mathrm{Cl})$ & & 160 & & 160 & 100 \\
\hline Total events & 8 & & 5 & & \\
\hline
\end{tabular}

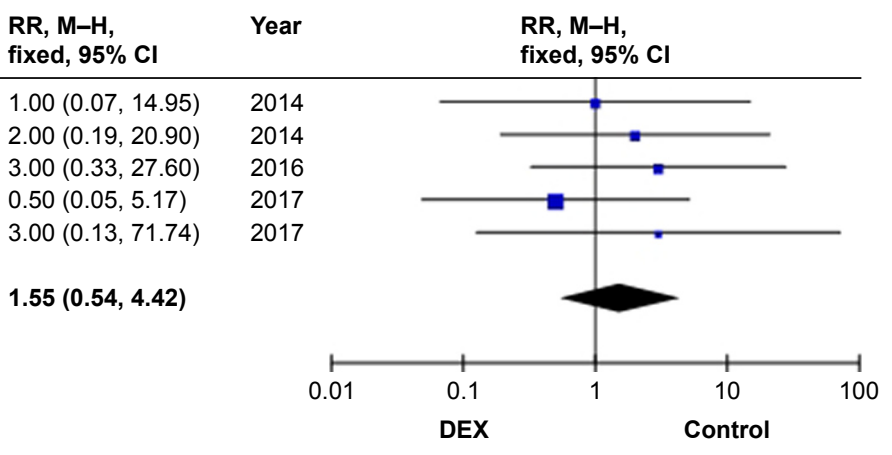

Figure 9 Forest plot for the incidence of bradycardia with and without DEX. Abbreviations: DEX, dexmedetomidine; RR, risk ratio; $M-H$, Mantel-Haenszel.

DEX could reduce the demand for opioids during cesarean section. ${ }^{18,19,30}$ This means that DEX may not only increase the incidence of PONV but also reduce the incidence of PONV during cesarean section.

There are some potential limitations associated with the included studies that should be considered when interpreting the results of our study. First, the number of included RCTs and the sample size were small, and thus, our conclusions are still based on a relatively small number of studies. Second, since we only included published literature, the search strategy could have also affected the results of this study. Third, the doses of DEX in the retrieved trials are varied. This demonstrated that the clinical use of DEX is not strictly regulated. Fourth, most of the studies included in this meta-analysis were conducted in China, and more studies conducted in different countries are still needed to confirm our findings. Additionally, further studies should be designed to demonstrate the effect of DEX on the neonatus.

\section{Conclusion}

This study showed that intrathecal DEX reduced the risk of shivering in patients undergoing cesarean section after spinal anesthesia and did not increase the incidence of PONV, hypotension, or bradycardia. However, the TSA indicated that further trials are still needed to confirm the abovementioned findings.

\section{Disclosure}

The authors report no conflicts of interest in this work.

\section{References}

1. Carrie LE. Extradural, spinal or combined block for obstetric surgical anaesthesia. Br J Anaesth. 1990;65(2):225-233.

2. Buvanendran A, Mccarthy RJ, Kroin JS, Leong W, Perry P, Tuman KJ. Intrathecal magnesium prolongs fentanyl analgesia: a prospective, randomized, controlled trial. Anesth Analg. 2002;95(3):661-666.
3. Braga AF, Braga FS, Potério GM, Pereira RI, Reis E, Cremonesi E. Sufentanil added to hyperbaric bupivacaine for subarachnoid block in Caesarean section. Eur J Anaesthesiol. 2003;20(8):631-635.

4. Lussos SA, Bader AM, Thornhill ML, Datta S. The antiemetic efficacy and safety of prophylactic metoclopramide for elective cesarean delivery during spinal anesthesia. Reg Anesth. 1992;17(3):126-130.

5. Kranke P, Eberhart LH. Possibilities and limitations in the pharmacological management of postoperative nausea and vomiting. Eur $J$ Anaesthesiol. 2011;28(11):758-765.

6. Crowley LJ, Buggy DJ. Shivering and neuraxial anesthesia. Reg Anesth Pain Med. 2008;33(3):241-252.

7. Roy JD, Girard M, Drolet P. Intrathecal meperidine decreases shivering during cesarean delivery under spinal anesthesia. Anesth Analg. 2004; 98(1):230-234

8. Graham AC, Mcclure JH. Quantitative assessment of motor block in labouring women receiving epidural analgesia. Anaesthesia. 2001; 56(5):470-476.

9. Bajwa SJ, Gupta S, Kaur J, Singh A, Parmar S. Reduction in the incidence of shivering with perioperative dexmedetomidine: A randomized prospective study. J Anaesthesiol Clin Pharmacol. 2012;28(1): 86-91.

10. Higgins JPT, Green S. Cochrane handbook for systematic reviews of interventions version 5.1.0 [updated March 2011]. The Cochrane Collaboration; 2011.

11. Moher D, Liberati A, Tetzlaff J, Altman DG; PRISMA Group. Preferred reporting items for systematic reviews and meta-analyses: the PRISMA statement. Int J Surg. 2010;8(5):336-341.

12. Higgins JP, Altman DG, Gøtzsche PC, et al. The Cochrane Collaboration's tool for assessing risk of bias in randomised trials. BMJ. 2011; 343: $\mathrm{d} 5928$.

13. Higgins JP, Thompson SG, Deeks JJ, Altman DG. Measuring inconsistency in meta-analyses. BMJ. 2003;327(7414):557-560.

14. Dersimonian R, Kacker R. Random-effects model for meta-analysis of clinical trials: an update. Contemp Clin Trials. 2007;28(2):105-114.

15. Brok J, Thorlund K, Gluud C, Wetterslev J. Trial sequential analysis reveals insufficient information size and potentially false positive results in many meta-analyses. J Clin Epidemiol. 2008;61(8):763-769.

16. Brok J, Thorlund K, Wetterslev J, Gluud C. Apparently conclusive meta-analyses may be inconclusive - Trial sequential analysis adjustment of random error risk due to repetitive testing of accumulating data in apparently conclusive neonatal meta-analyses. Int J Epidemiol. 2009;38(1):287-298.

17. Wetterslev J, Thorlund K, Brok J, Gluud C. Trial sequential analysis may establish when firm evidence is reached in cumulative meta-analysis. J Clin Epidemiol. 2008;61(1):64-75.

18. Li Z, Tian M, Zhang CY, et al. A Randomised Controlled Trial to Evaluate the Effectiveness of Intrathecal Bupivacaine Combined with Different Adjuvants (Fentanyl, Clonidine and Dexmedetomidine) in Caesarean Section. Drug Res. 2015;65(11):581-586. 
19. Sun Y, Xu Y, Wang GN. Comparative Evaluation of Intrathecal Bupivacaine Alone, Bupivacaine-fentanyl, and Bupivacaine-dexmedetomidine in Caesarean Section. Drug Res. 2015;65(9):468-472.

20. Qi X, Chen D, Li G, et al. Comparison of Intrathecal Dexmedetomidine with Morphine as Adjuvants in Cesarean Sections. Biol Pharm Bull. 2016;39(9):1455-1460.

21. Nasseri K, Ghadami N, Nouri B. Effects of intrathecal dexmedetomidine on shivering after spinal anesthesia for cesarean section: a double-blind randomized clinical trial. Drug Des Devel Ther. 2017;11:1107-1113.

22. He L, Xu JM, Liu SM, Chen ZJ, Li X, Zhu R. Intrathecal Dexmedetomidine Alleviates Shivering during Cesarean Delivery under Spinal Anesthesia. Biol Pharm Bull. 2017;40(2):169-173.

23. Bi YH, Cui XG, Zhang RQ, Song CY, Zhang YZ. Low dose of dexmedetomidine as an adjuvant to bupivacaine in cesarean surgery provides better intraoperative somato-visceral sensory block characteristics and postoperative analgesia. Oncotarget. 2017;8(38):63587-63595.

24. Mantz J, Josserand J, Hamada S. Dexmedetomidine: new insights. Eur J Anaesthesiol. 2011;28(1):3-6.

25. Wagner DS, Brummett CM. Dexmedetomidine: as safe as safe can be Seminars in Anesthesia, Perioperative Medicine and Pain. 2006;25(2): 77-83.

26. Shaikh SI, Mahesh SB. The efficacy and safety of epidural dexmedetomidine and clonidine with bupivacaine in patients undergoing lower limb orthopedic surgeries. J Anaesthesiol Clin Pharmacol. 2016;32(2): 203-209.

27. Yq L, Feng YY, Yd L. Comparation of effect of dexmedetomidine and propofol in patients with caesarean section. Practical Pharmacy and Clinical Remedies. 2015;18:920-922.

28. Hong JY, Lee IH. Comparison of the effects of intrathecal morphine and pethidine on shivering after Caesarean delivery under combinedspinal epidural anaesthesia. Anaesthesia. 2005;60(12):1168-1172.

29. Park SM, Mangat HS, Berger K, Rosengart AJ. Efficacy spectrum of antishivering medications: meta-analysis of randomized controlled trials. Crit Care Med. 2012;40(11):3070-3082.
30. Bao Z, Zhou C, Wang X, Zhu Y. Intravenous dexmedetomidine during spinal anaesthesia for caesarean section: A meta-analysis of randomized trials. J Int Med Res. 2017;45(3):924-932.

31. Doufas AG, Lin CM, Suleman MI, et al. Dexmedetomidine and meperidine additively reduce the shivering threshold in humans. Stroke. 2003;34(5):1218-1223.

32. Bicer C, Esmaoglu A, Akin A, Boyaci A. Dexmedetomidine and meperidine prevent postanaesthetic shivering. Eur J Anaesthesiol. 2006; 23(2):149-153.

33. Elvan EG, Oç B, Uzun S, Karabulut E, Coşkun F, Aypar U. Dexmedetomidine and postoperative shivering in patients undergoing elective abdominal hysterectomy. Eur J Anaesthesiol. 2008;25(5):357-364.

34. Paris A, Tonner PH. Dexmedetomidine in anaesthesia. Curr Opin Anaesthesiol. 2005;18(4):412-418.

35. Talke P, Tayefeh F, Sessler DI, Jeffrey R, Noursalehi M, Richardson C. Dexmedetomidine does not alter the sweating threshold, but comparably and linearly decreases the vasoconstriction and shivering thresholds. Anesthesiology. 1997;87(4):835-841.

36. Heesen M, Klimek M, Hoeks SE, Rossaint R. Prevention of spinal anesthesia-induced hypotension during cesarean delivery by 5-hydroxytryptamine-3 receptor antagonists: a systematic review and meta-analysis and meta-regression. Anesth Analg. 2016;123(4): 977-988.

37. Langesaeter E, Rosseland LA, Stubhaug A. Continuous invasive blood pressure and cardiac output monitoring during cesarean delivery: a randomized, double-blind comparison of low-dose versus high-dose spinal anesthesia with intravenous phenylephrine or placebo infusion. Anesthesiology. 2008;109(5):856-863.

38. Yousef AA, Salem HA, Moustafa MZ. Effect of mini-dose epidural dexmedetomidine in elective cesarean section using combined spinalepidural anesthesia: a randomized double-blinded controlled study. J Anesth. 2015;29(5):708-714.

\section{Publish your work in this journal}

Drug Design, Development and Therapy is an international, peerreviewed open-access journal that spans the spectrum of drug design and development through to clinical applications. Clinical outcomes, patient safety, and programs for the development and effective, safe, and sustained use of medicines are the features of the journal, which

\section{Dovepress}

has also been accepted for indexing on PubMed Central. The manuscript management system is completely online and includes a very quick and fair peer-review system, which is all easy to use. Visit http://www.dovepress.com/testimonials.php to read real quotes from published authors.

Submit your manuscript here: http://www.dovepress.com/drug-design-development-and-therapy-journal 